\title{
A Book Review
}

on

Population, Health and Development: Perspectives on Uttarakhand

T.V. Sekher, Abhishek Singh and Sulabha Parasuraman (Editors)

New Delhi: Academic Foundation

in association with

International Institute for Population Sciences, Mumbai, 2013, 558 pp.

Keshab Prasad Adhikari*

The population-health-environment approach to development recognizes the interconnectedness between people and their environment. Papers included in this book attempted to examine these issues in detail with evidences and identify areas of further search and action in the state of Uttarakhand of India. The volume is the outcome of a collection of papers presented in a three-day (March 17-19, 2008) seminar entitled 'Population, Environment and Development in Uttarakhand' organized by the International Institute for Population Sciences (IIPS), Mumbai in Dehardun. The main thrust of this volume is to see how population growth, size, fertility, mortality, migration, settlement patterns, and resource availability influence the environment and development. It demands a better understanding of solving such interwoven complex challenges through a better understanding of two-way impact of population factors to the environment and environmental changes on human health and well-being. Papers included in the volume found giving ample evidence, issues, knowledge and methodologies for the successful and effective integration of population and environmental factors to achieve ranges of development goals like poverty reduction, health security to gender equity and environmental protection.

The volume comes as a compilation of 27 selected papers submitted and presented in the seminar. Besides, it contains one overarching paper 'Population, Health and Development in Uttarakhand: Issues and Challenges from the editors' sides. The 27 papers are re-grouped into seven broader thematic issues of education, employment and income inequality, fertility and family planning, health service utilisation, gender issues, HIV/AIDS, urbanisation and migration and population and development of Uttarakhand state of India. Most of the papers provided comprehensive analysis by utilizing the most recent available data and information from official statistics, National Family Health

*Dr. Adhikari is Associate Professor of Population Studies at Tribhuvan University and also been working as the Program Coordinator of Labour Studies at Tribhuvan University. He is also current president of Population Association of Nepal (PAN). 
Surveys, District Level Household and Facility Surveys, National Sample Surveys and Censuses of India. The overview paper presents a clear picture of emerging issues and challenges in the population, health and development of Uttarakhand.

The overview paper presenting a snap-short geo-political background and ranking economic and development level of the state compared to other states of India attempted to focus on the analysis of size, growth, distribution and composition of the state's population. As of the 2011 population census the state was resided by 10.1 million populations with the access of 4 males per 100 females. The decadal population growth rate between 2001 and 2011 is nearly 2 percent and on average, 189 persons are residing in per square kilometre area of the state. Information on missing girls (deficit of 115 girls per 1000 boys aged 0-6 years) is a severe social challenge in the state (Table 3). The state is doing well in the achievement of universal access to education, urbanizing the population and economy. In a decadal difference, the female literacy rate increased by 11 percentage points from 60 percent in 2001 to 71 percent in 2011.

Household assets and characteristics indicated that 34 percent of the state's population is below the poverty line (having below poverty line card). Concerning basic infrastructure, primary and middle schools are available in 98 percent and accredited social health activists (SHA) in 75 percent villages of the state, however, any type of government health facilities are available only in 30 percent villages of the state. Prevalence of child marriage among women (married below age 18 years) in the state is below six percent, 99 percent of female population are aware on any family planning method with 61 percent contraceptive prevalence rate of any method and 20 percent unmet need for family planning. However, only 30 percent of delivery in the state takes place in health institutions. Child health statistics indicated that 63 percent of children in the state are fully immunised.

The chapter presents an overview of the state's health and population policy of 2002. The state is first in India to formulate integrated health and population policy aimed to initiate health sector reform. The overall mission and goal of the policy was to made efforts to improve the health status and quality of life of the population, eliminate inequalities in access to health care, address emerging health concerns and stabilise population growth. The paper finds population and health indicators of the states' better than many other Indian states and outlines the state's health systems facing several challenges in providing sufficient, appropriate and quality health services reaching marginal populations. Such challenges include scattered settlements in difficult terrain, inadequate infrastructure facility and lack of human and financial resources.

The volume comprises of five papers under the thematic group 'Education, Employment and Income Inequalities' contributed by 12 scholars. The first three papers are on universal education and the second two on employment and income inequality. 
The first paper by Suresh Sharma and Nilabja Ghosh entitled 'Education for All in Rural Himalayas: A study of Uttarakhand' through the exploratory and explanatory analysis and presentation of data derived from 'Socio-economic status survey of Uttarakhand, June-July 2004' attempted to add knowledge claim in the ground of narrowing gender and caste gap in education in coming years among young age population. The statistical test exhibited that caste disparity in access to education is in-significant for populations aged 20 years and below and significantly persisted for 20 years and older however, sex disparity persists at all ages and concludes that access to education is explained by locations, age, gender, caste and religion attributes of populations.

Paper second 'Elementary Education in Uttarakhand State' by Sandeep Kumar Sharma, Manju Rani and Ravendra K. Sharma analyzing data from 2001 Population Census and All India Education Survey 2002 concluded that the state made significant progress in the field of education. Commendable efforts are made in educating all children aged 6-14 years, but the dream of achieving 100 percent elementary education was still demanding efforts and resources to pour. In the third paper, 'Who Gets Education in Uttarakhand? Analysis of NFHS-3 Data' by Nandita Saikia, Jayanta Kumar Bora, and F. Ram analysed data of 1991 and 2001 Population censuses and National Family and Health Survey 2005-06 exhibited school attendance rate at lower primary level is satisfactory for the children of different sections of the society. As the educational level increases, the school attendance rate of the children of different socioeconomic groups becomes distinct. Therefore, it is imperative to take various measures to retain children of varied communities in schools as the education level increases above primary level.

The fourth paper by Bhagwan S. Bisht 'The Unorganized Sector Workers in Uttarakhand: A Need for Policy Intervention' utilises data from a sample study of 8,643 unorganised sector workers engaged in the tourism sector, brick kilns, sand quarries, security services and construction workers. Data revealed that the states' unorganized sector workers live a very modest life without basic amenities like fuel wood, drinking water, light, toilets and healthy shelter. They are abstained from the basic services of education, recreation, modern facilities, hygiene, sanitation and medical facilities, nutrition and cover of the accidental risks, work an inhuman situation. For the improvement of such pathetic working and living conditions of these workers Bisht made policy attracting recommendations and suggestions for a plan of actions. Paper five by Nilabja Ghosh, Sabyasachi Kar and Suresh Sharma 'Inequalities of Income Opportunities in a Hilly State: A Study of Uttarakhand' is developed utilising data from official sources and a fresh sample survey of three clusters of three districts. The paper clearly showed that income inequality tends to widen by the level of workers' skill and 
education. Skilled and educated workers draw higher level of income than unskilled and uneducated at a significantly explainable level. Besides skill and education urban-rural residence and geographical locations also matters in explaining the income inequalities among workers.

Fertility and Family Planning is included as the second broader thematic area in the volume and comprises four papers by nine eminent contributors. The first paper on this theme and sixth of the volume 'Age at Marriage in Uttarakhand: Changing Perspective and Role of Family System' by Ravi Prakash and SulabhaParsuraman utilised population census data of 2071 to 2001 and District Level Reproductive and Child Health Survey (DLHS-RCH) 2002/04 data. Findings of the paper cleared that over the year the proportion single population is increasing, especially at younger age (below 30) for both sexes. This led to an increase in age at marriage in the state. But the study unveiled fact for the further exploration of why the amount of marriage below the legal age in the nuclear family is high compared to the joint families. The seventh paper 'Economic Differentials of Fertility and Utilisation of Maternal and Child Health Services in Uttarakhand' by C.V. S. Prasad and Jalandhar Pradhan, through the analysis of National Family Health Survey-3 (2005-06), presented an impetus that family's economic status and female education are the two most important determinants of fertility in the state, within this economic variables emerged as the higher contributing factor than that of female education. The paper suggests some practicable family welfare measures targeting younger couples for better demographic impacts. Paper 'Unwanted Pregnancy: A Comparative Study of Uttarakhand and Himachal Pradesh' by SujitaGanguly and Sayeed Unisa also using National Family Health Survey-3 (2005-06) data unveiled the fact that unwanted pregnancy in Uttarakhand is high compared to Himachal Pradesh as explained by various demographic, social and economic factors such as a rural biased sample, belonging to Hindu religion, some lower level of educational attainment, comparatively low level of women's autonomy and mass media. This comparative study gave impetus to attain socio-economic, demographic, and women's status to eliminate the context of bearing unwanted pregnancies. Paper 'Communication, Accessibility and Condom Use: Insights from Uttar Pradesh and Uttarakhand, NFHS-3, 2005-06' established that mass media emerges as the most significant factor for influencing condom use in Uttarakhand than Uttar Pradesh. With the findings of this comparative analysis, the paper postulates some of the practicable policy measures to improve the contraceptive prevalence rate in UP for the improvement in demographic indicators of fertility and young age mortality.

The third broader thematic area 'Utilisation of Health Services' comprises five scientific papers contributed by nine academicians and researchers. Paper 'Interactions with Health Workers and Reproductive Behaviour: Evidence for Uttarakhand' by 
Puspita Datta and Chayan Roy Choudhury evidenced that the role of health workers directly interacting with the clients has a commendable impact on facilitating the contraceptive beliefs and behaviours. However, factors determining the poor health service delivery in the state are difficult hilly terrain, scattered settlements, inadequate infrastructure and lack of needed human resources. Paper suggest for best utilisation of the available scarce human and material resources for bringing about change in reproductive behaviour for improved family status and demographic indicators. Paper 'Inhibiting Factors in the Utilisation of Public Health Care Services by the Rural People in Uttarakhand' by Anita Bhargava and SatyabanSahuthrough the analysis of National Family Health Survey-3 (2005-06) data attempted to justify that the health service facilities in the state are challenged by physical, socio-economic and cultural factors. The findings are with policy recommendations to capacitate local governance units in rural areas to make the public health care services for the extensive and efficient utilisation by the rural and remote people. The paper 'Home to Institutional Deliveries: A Long Perspective in Uttarakhand' by Sanjay Rode is developed using data of District Level Reproductive Child Health (DLHS-RCH)Household Survey. Fitting multinomial logit regression model, the paper explained that home deliveries are more constrained in rural areas because of distance between health facilities and house of clients. Another paper, 'Understanding the determinants of Breastfeeding Practices and its Discontinuation in Uttarakhand' by Archana Kujur and SulabhaParsuraman, came to a concluded that breastfeeding improves immunity level in children, protect from frequent diseases like diarrhoea and reduces morbid conditions and probability of mortality among children. But the state of breastfeeding in Uttarakhand is lower (90\% of children ever breastfeed) compared to the national average of India (94\%) and other states. Findings indicated that an increase in mother's educational attainment is not necessarily associated to an increase in the percentage of the children breastfeeding. Rather improvement in education and sex of child determines the discontinuation of breastfeeding. The fourteenth paper of the volume 'Social Health Insurance and Social Security in Uttarakhand' by Avishek Hazra and Subrata Lahiri exhibited that health insurance coverage in general and social health insurance in Uttarakhand is better than other state and the national average of India. Though there is an immense challenge for the expansion of its coverage among the large number of informal sector workers, addressing social inequalities, regional disparities, unemployment and poverty are major issues to cover. 
Three papers incorporated under broader theme 'Gender Issue' contributed by three authors* attempted to assess the indicators to measure women's empowerment, gender-based violence and consequences on the sexual and reproductive health and inequalities in maternal and child health care in selected states of India. All three papers using data from National Family Health Survey -3 (2005-06), concluded that level of women's empowerment from the viewpoint of participation in decision making, access to financial resources and freedom of movement is below the national average of India and varied by education and occupation of women and family's wealth status. The paper further unveiled a fact that one-fourth of women found to express to have ever experienced physical violence and around five percent sexual violence. Inequality in maternal-child health indicators vary by wealth status and different social groups of the population. Besides caste and wealth status, age and educational level of women, religion and birth order explain the level of inequalities in maternal and child health care in selected states of India.

The fifth broader thematic area 'HIV/AIDS' comprises two thematic papers on perceived risk and vulnerability to HIV of youth and HIV/AIDS awareness among teachers. Papers concluded that youths in Uttarakhand are vulnerable to HIV, comprised of different vulnerable groups. Groups vary by sex, and socio-cultural factors. There persists a fairly high level of understanding among youths about various measures to prevent HIV infections. Both male and female, married and unmarried and residents of rural or urban areas, schoolteachers, are aware of general information, symptoms, effects and modes of transmission, prevention and treatment of HIV/AIDS. HIV/AIDS related taboos are almost none in the teachers and are with positive attitudes towards persons with HIV. These papers come up with practicable policy and behavioural implications to have halted HIV transmission in the state and to be replicated in other similar regions in general.

Sixth thematic area 'Urbanisation and Migration' includes three scientific papers 'Spatial Pattern of Urbanisation and Urban Growth in Western Himalayan Regions in India' by Soumya Mohanthy and R.B. Bhagat; 'Migration and Workforce Participation in the Himalayan States' by R. Lusome and R. B. Bhagat and 'Urbanisation: New Challenges in Uttarakhand' by Anup Badola. Paper by Mohanty and Bhagat uses secondary data obtained from censuses and office of the Registrar General of India for the period of 1981-2001; the paper by Lusome, Bhagat and Badola developed papers based on analysis of population census data of 2001. Analysis of the spatial pattern of urbanisation and urban growth in Himalayan regions revealed that states Jammu and Kashmir are urbanized at par of the national Level, the state Uttarakhand is also scaling 
up its pace of urbanisation as indicated by the remarkable increase in the share of the population residing in class 'I' cities to the total urban population of the state. In totality, the urban population in the hill towns is distributed unevenly by size and class of cities. Frontier cities are growing faster; expansion of class 'I' cities is noticeable than small ones. Findings draws attention of policy planning and politics to address uneven patterns of urbanisation in Western Himalayan states. Analysis of migration and workforce pattern in the Himalayan states showed diverse migration pattern in the states, though are of the similar topographical character. States Himachal Pradesh and Sikkim observed the greater interdental migration flow. Major flow of the migrants is that of the working age-groups. This implied that work-force migration overwhelms the in-migrating states. States Himachal and Sikkim emerged as in-migrating and states Uttarakhand, and Jammu and Kashmir as out-migrating states. Added new challenges of urbanization in Uttarakhand called for policies addressing growing slums and poorer, revisiting of the public distribution systems (PADS), management of population compared to the size of declining cultivated land, increased need of urban health facilities and educating the population of urban settings.

The last but not least seventh thematic group 'Population and Development' comprises five scientific papers contributed by eight academicians and researchers. Most of the papers are developed based on national population census data of 2001, National Family Health Survey-3 (NFHS-3), District Level Household Survey (DLHS), Uttarakhand Update, and Sample Surveys of Habitations (2003 and 2006). The author of the paper 'Population and Development in Uttarakhand' concludes that the state Uttarakhand is with immense potential for becoming leading in the integration of population and development issues in India through the exploration and best utilization of both human and natural resources. Paper 'Population Growth and Land Use in Uttarakhand' by Dewaram A. Nagdeve analyzed inter-district variation in land use patterns in the state. The paper concludes that in totality, the net shown area and fallow land found increased and the forest covered area declined over the study period. 'Tribes of Uttarakhand: Comparative Study' by Ravendra K. Sharma, D.C. Jain and Manju Rani found tribal population not uniformly distributed in the state of Uttarakhand. Most of the tribal communities are concentrated in a certain locality like Udham Singh Nagar and Dehradun district. Settlements of Bhotias scattered over the state and Rajis and Jannasaris in few pockets. Problems associated to tribal population include imbalance sex ratio in the child population, a vast difference in literacy and educational attainment and occupational distribution. Presentation of the state of arts of the availability and quality of drinking water in the state of Uttarakhand showed several areas of intervention to remove the problems of water scarcity, improve accessibility, quantity 
and quality of water. Paper 'Population Ageing in Uttarakhand: Salient Demographic and Spatial Characteristics and Policy Implications' by Hemkhothang Lhungdim through the analysis of decadal census data from 1981 to 2001 concluded that the population of the state shown signs of ageing. This implied that the expectation of life after age 60 is increasing significantly in the state. This ageing sign calls for cost implacable social, health and aged care policies in the state.

In conclusion, every paper included in the volume found to be developed utilizing rich sources of database and sound methodological procedures. Findings are imperatives in generating new knowledge in the ground of population, health and development debate in similar socio-economic and cultural settings like Nepal. It justifies the claims of book editors 'this edited book will serve as a ready reference material' for professionals of academia, policy and planning in different sectors of population, health, environment and the others as relevant. Consistencies in formatting, documentation and style of presentation are matters to take as references while compiling similar types of volume. The volume is published in the year 2013, most papers (except overview paper) are based on a relatively older data base. It would have been better if data of recent censuses were updated. New and emerging issues in population and development such as opportunities opened by the changing age structure of population viz., demographic dividend (window of opportunity) found as missing part. However, some discussion in the issues of population ageing is attempted to made. Sex imbalances and missing girl child is seen serious policy intervention subject in the state.

\section{References}

Sekher, T.V. A. Singh and S. Parasuraman (eds.) (2013). Population, health and development: Perspectives on Uttarakhand. New Delhi: Academic Foundation in Association with International Institute for Population Sciences, Mumbai. 